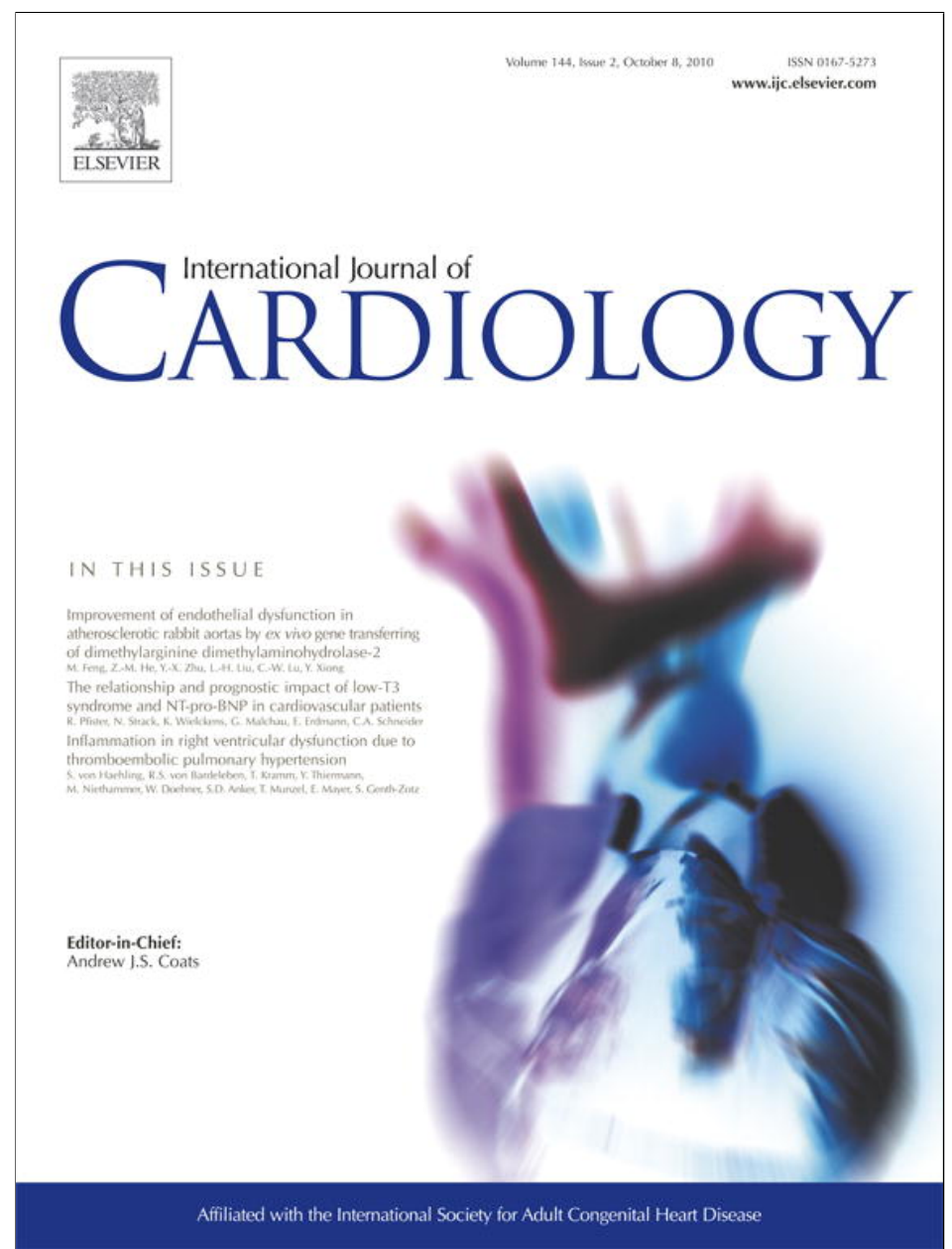

This article appeared in a journal published by Elsevier. The attached copy is furnished to the author for internal non-commercial research and education use, including for instruction at the authors institution and sharing with colleagues.

Other uses, including reproduction and distribution, or selling or licensing copies, or posting to personal, institutional or third party websites are prohibited.

In most cases authors are permitted to post their version of the article (e.g. in Word or Tex form) to their personal website or institutional repository. Authors requiring further information regarding Elsevier's archiving and manuscript policies are encouraged to visit:

http://www.elsevier.com/copyright 
Review

\title{
Acute heart failure: Multiple clinical profiles and mechanisms require tailored therapy
}

\author{
Marco Metra ${ }^{\mathrm{a}, *},{ }$, G. Michael Felker ${ }^{\mathrm{b}}$, Valerio Zacà ${ }^{a}$, Silvia Bugatti ${ }^{\mathrm{a}}$, Carlo Lombardi ${ }^{\mathrm{a}}$, Luca Bettari ${ }^{\text {a }}$, \\ Adrian A. Voors ${ }^{c}$, Mihai Gheorghiade ${ }^{\mathrm{d}}$, Livio Dei Cas ${ }^{\text {a }}$ \\ a Cardiology, Department of Experimental and Applied Medicine, University of Brescia, Italy \\ ${ }^{\mathrm{b}}$ Duke Clinical Research Institute, Durham, NC 27705, USA \\ c Department of Cardiology, University Medical Center Groningen, The Netherlands \\ ${ }^{\mathrm{d}}$ Northwestern University Feinberg School of Medicine, Chicago, IL 60611, USA
}

\section{A R T I C L E I N F O}

\section{Article history:}

Received 6 November 2009

Accepted 2 April 2010

Available online 26 May 2010

\section{Keywords:}

Acute heart failure

Pathophysiology

Prognosis

Therapy

Comorbidities

\begin{abstract}
A B S T R A C T
Acute heart failure (HF) is the most common diagnosis at discharge in patients aged $>65$ years. It carries a dismal prognosis with a high in-hospital mortality and very high post-discharge mortality and re-hospitalization rates. It is a complex clinical syndrome that cannot be described as a single entity as it varies widely with respect to underlying pathophysiologic mechanisms, clinical presentations and, likely, treatments. It is the aim of this paper to describe some of the main clinical presentations of acute HF. Amongst them, we will consider de novo HF versus acutely decompensated chronic HF, HF caused, and/or worsened, by myocardial ischemia, acute HF with low, normal, or high systolic blood pressure, acute HF caused by lung congestion or fluid retention or fluid redistribution to the lungs, and acute HF with comorbidities (diabetes, anemia, renal insufficiency, etc.). Different pathophysiologic mechanisms and clinical presentations may coexist in the same patient. Identification and, whenever possible, treatment of underlying pathophysiologic mechanisms may become important for acute $\mathrm{HF}$ management.
\end{abstract}

(c) 2010 Elsevier Ireland Ltd. All rights reserved.

\section{Introduction}

Acute heart failure (HF) is the most common diagnosis at discharge in patients aged $>65$ years. It carries a dismal prognosis with an inhospital mortality rate of 3-8\%, a 60-90 day mortality rate of 9-13\%, and a short-term re-hospitalization rate of $25-30 \%$ [1-7]. Acute HF is a complex clinical syndrome that may vary widely with respect to underlying pathophysiologic mechanisms and clinical presentations and, as such, it resists straightforward definition and classification. A cardiac cause of symptoms and urgency of care are, however, present in all the forms of acute HF and, thus, despite some controversies [8], this definition maintains its validity.

Treatment of acute HF remains a major challenge of current clinical practice and the heterogeneity of acute HF is likely one of the major causes of these difficulties. It is highly unlikely that a single treatment algorithm may be feasible for all the patients with acute HF. At present, we lack sufficient tools to identify different pathophysiologic mechanisms (i.e. hemodynamic abnormalities, myocardial ischemia, renal dysfunction, neurohormonal activation, inflammation, etc.) and to target treatment accordingly.

\footnotetext{
* Corresponding author. Tel.: + 390303995572; fax: + 390303700359. E-mail address: metramarco@libero.it (M. Metra).
}

We will herein describe some of the more common clinical scenarios of acute HF and highlight their implications with regards pathophysiology and treatment. It is our belief that treatment of acute HF directed at specific pathologic targets may influence both inhospital and post-discharge outcomes.

\section{Clinical scenarios in European guidelines}

According to the 2005 European Society of Cardiology (ESC) guidelines on acute HF [9] and the more recent ESC HF guidelines [8], acute HF is defined as "a rapid onset or change in the signs and symptoms of HF, resulting in the need for urgent therapy." These guidelines then point out the heterogeneity of this syndrome indicating that it may be either new onset HF or worsening of pre-existing HF and that cardiac dysfunction may be related to different causes, including acute coronary syndromes (ACS), valve dysfunction, arrhythmias, pericardial disease, and increased left ventricular (LV) afterload and that these different causes may interact $[1,8,9]$.

The potential clinical presentations of acute HF have been classified in the ESC guidelines (Table 1) [8]. Amongst the 3580 patients with acute HF enrolled in the recent EuroHeart Failure Survey (EHFS) II, by adopting the aforementioned classification, 2340 (65.4\%) presented with decompensated HF, 407 (11.4\%) with hypertensive HF, 581 (16.2\%) with pulmonary oedema, 139 (3.9\%) with cardiogenic shock, and 113 (3.2\%) with isolated right HF [4]. In this review, we will 
Table 1

Clinical classification of acute heart failure in the ESC guidelines.

\begin{tabular}{|c|c|}
\hline Condition & Characteristics \\
\hline $\begin{array}{l}\text { Worsening or } \\
\text { decompensated chronic } \\
\text { heart failure }\end{array}$ & $\begin{array}{l}\text { - History of heart failure } \\
\text { - Progressive worsening } \\
\text { - Systemic and pulmonary congestion }\end{array}$ \\
\hline Acute pulmonary oedema & $\begin{array}{l}\text { - Severe dyspnea and orthopnoea } \\
\text { - Pulmonary rales }\end{array}$ \\
\hline Hypertensive heart failure & $\begin{array}{l}\text { - High blood pressure } \\
\text { - Relatively preserved left ventricular function } \\
\text { - Pulmonary edema with or without fluid overload }\end{array}$ \\
\hline Cardiogenic shock & $\begin{array}{l}\text { - Hypotension (systolic blood pressure }<90 \mathrm{~mm} \\
\text { Hg or a drop of mean arterial pressure }>30 \mathrm{~mm} \mathrm{Hg} \text { ) } \\
\text { - Absent or low diuresis }(<0.5 \mathrm{~mL} / \mathrm{kg} / \mathrm{h}) \\
\text { - Evidence of organ hypoperfusion and pulmonary } \\
\text { congestion }\end{array}$ \\
\hline Isolated right $\mathrm{HF}$ & $\begin{array}{l}\text { - Low output syndrome } \\
\text { - Absence of pulmonary congestion and low LV filling } \\
\text { Pressures } \\
\text { - Increased jugular venous pressure, with or without } \\
\text { hepatomegaly }\end{array}$ \\
\hline \multicolumn{2}{|c|}{ Associated with acute coronary syndrome ${ }^{\mathrm{a}}$} \\
\hline With an arrhythmia & Bradycardia, atrial fibrillation, ventricular tachycardia \\
\hline
\end{tabular}

describe some clinical factors which may influence and cause these clinical presentations. Importantly, more than one factor may coexist in the same patient.

\section{De novo acute heart failure versus decompensation of chronic heart failure}

Acute decompensated HF may present either as new onset (de novo) HF, i.e. as first manifestation of cardiac disease, or as decompensation of chronic HF (ADCHF) and these two forms differ. Data from the EHFS II indicate that, when compared to ADCHF subjects, patients with de novo acute HF more frequently present with acute pulmonary edema ( $26 \% \mathrm{vs}$. $10.4 \%$ ) and cardiogenic shock ( $6.8 \%$ vs. $2.2 \%$ ), are hypertensive on admission, and are more likely to have an acute coronary syndrome (ACS) as a precipitating factor (42\% vs. $23 \%$ ) [4]. Patients with de novo acute HF are, however, less likely to have a history of prior myocardial infarction (MI) as well as comorbidities (diabetes mellitus, renal failure, chronic obstructive pulmonary disease, and anemia). Consistent results have been also observed in the Italian Acute Heart Failure Survey [3]

With respect to prognosis, short-term mortality data do not substantially differ among these two clinical profiles. In-hospital mortality appears to be similar [3] or higher ( $8.1 \%$ vs. $5.8 \%$ in the EHFS II) [4] in subjects with de novo acute HF, most likely because of the higher prevalence of cardiogenic shock in such patients. In the Acute Decompensated Heart Failure National Registry (ADHERE) a previous history of chronic HF was not shown to be an independent predictor of in-hospital mortality [10].

Post-discharge prognosis appears to be better in patients with de novo acute HF and this trend is likely due, at least partially, to the more frequent presence of reversible causes (ACS, hypertension, etc.) and to the lower prevalence of comorbid conditions in the patients with new onset HF compared to those with ADCHF. In the Italian registry, post-discharge mortality at 6 months was $8.4 \%$ in de novo acute HF patients as compared to $16.0 \%$ in patients with pre-existing chronic HF, and re-hospitalization rate was slightly lower in the former group (38.1\% vs. $41 \%$ ) [3]. In the Etude Francaise de l'Insuffisance Cardiaque Aigue (EFICA), the history of a prior episode of worsening HF was an independent predictor of mortality at 1 month from admission in 392 patients without cardiogenic shock, consistent with a better clinical course in patients with new onset $\mathrm{HF}$ [6]. In a cohort of 497 consecutive patients admitted to our institute for acute HF, 307 (62\%) with ADCHF and 190 (38\%) with de novo acute HF, we observed a worse prognosis, with a higher incidence of death and HF rehospitalization during a mean follow-up of 387 days, in the patients with ADCHF.

\section{Myocardial ischemia and necrosis}

Ischemic heart disease is the most common cause of HF in Europe and in the United States. Data from large registries indicate that a history of ischemic heart disease is present in up to $45-60 \%$ of patients admitted for acute HF. Nearly $40 \%$ of patients with acute HF have experienced a prior MI, the highest prevalence being observed in subjects with ADCHF [2-6]. Ischemic etiology has been consistently reported as an important predictor of increased mortality risk in chronic HF [11]. Conversely, in acute HF, ischemic etiology has not been often found to be an independent prognostic variable unless when associated with cardiogenic shock. It is possible that the potential prognostic role of acute myocardial ischemia may be affected by the use of coronary revascularization procedures, and that these may diminish the negative effects of ischemia [12].

There are many potential connections between coronary artery disease and acute. Myocardial ischemia and myocyte necrosis may constitute either a trigger for acute HF (i.e., ACS leading to HF), or alternatively the HF event itself may lead to myocardial ischemia or necrosis in the absence of frank ACS. ACS are the precipitating cause of acute HF in $20-30 \%$ of patients, mainly in de novo acute HF patients. The role of ACS as the pathogenic mechanism of acute HF may vary according to the clinical scenario being greater in acute pulmonary edema and cardiogenic shock (Fig. 1) [4]. More specifically, ST elevation ACS account for more than half of the cases of cardiogenic shock, the clinical profile of acute HF associated with the highest in-hospital mortality rate [4].

On the other hand, myocardial ischemia and necrosis may occur during an episode of acute HF as a consequence of a transient reduction in coronary perfusion due to increased left ventricular filling pressure, reduced systemic arterial blood pressure, tachycardia, coronary vasoconstriction and endothelial dysfunction mediated by neurohormonal activation (angiotensin, norepinephrine, and endothelin), inflammatory mechanisms and platelet activation (Fig. 2) [13]. Subjects with preexisting coronary artery disease are particularly vulnerable especially because of the possible presence of areas of hibernating myocardium, but ischemia may also occur in patients with non-ischemic cardiomyopathy and normal coronary arteries [14,15]. We recently reported an increase of plasma troponin $\mathrm{T}$ to detectable plasma levels, measured serially after admission for acute HF, in $53 \%$ of patients with ischemic heart disease and in $40 \%$ of patients with normal coronary arteries [15].

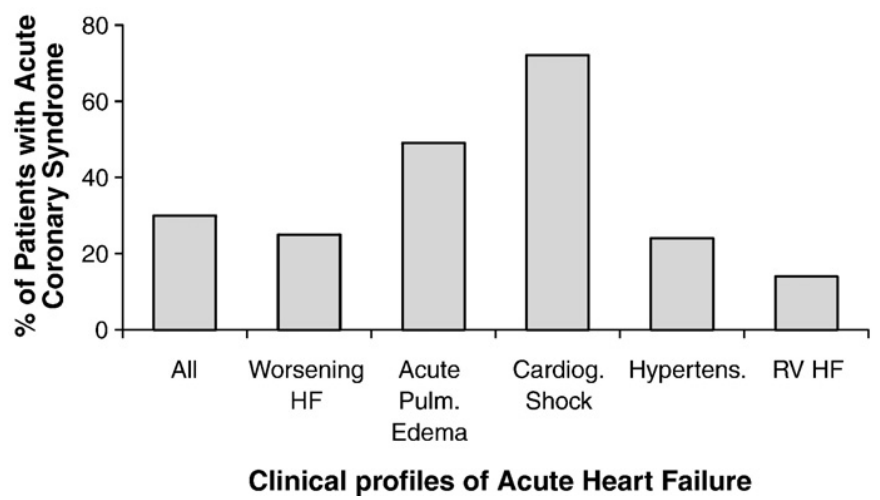

Fig. 1. Proportion of patients with an acute coronary syndrome as the precipitating factor of acute heart failure (adapted from Ref. [4]). 


\section{Acute HF}

Hemodynamic abnormalities + neurohormonal-inflammatory activation

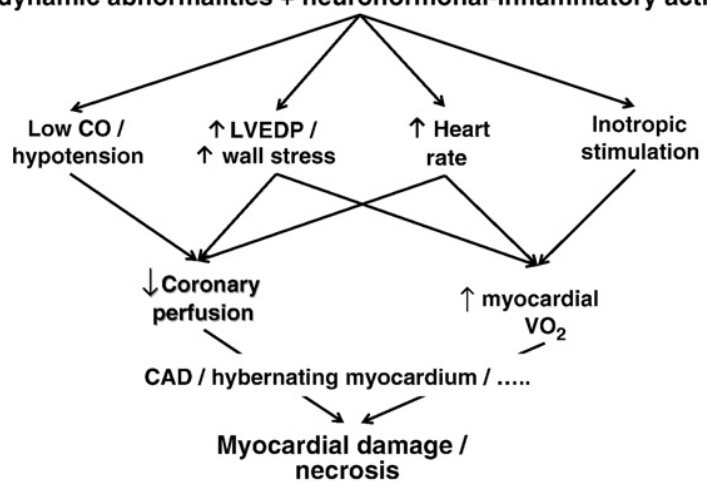

Acute $\mathrm{HF}+$ traditional inotropic agent

Hemodynamic abnormalities + neurohormonal-inflammatory

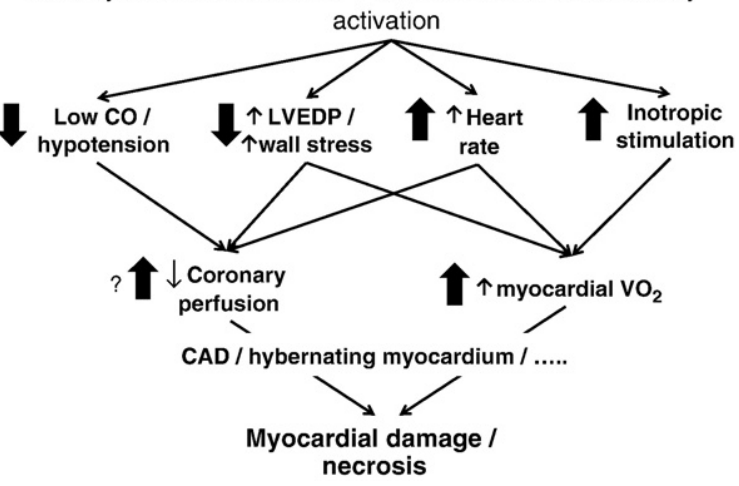

Fig. 2. Mechanisms of myocardial damage in patients with acute heart failure (top) and potential effects of traditional inotropic agents (bottom).

The clinical relevance of myocardial necrosis in heart failure has been demonstrated by studies based on plasma troponin measurements. An increase of plasma troponin levels has been reported in $40 \%$ to $70 \%$ of patients admitted for acute HF [15-17], depending on the study population and assay utilized. The lower proportion (6.2\%) found in the ADHERE registry, including 84,872 patients with acute HF, may be related to troponin measurements only at the time of admission [14].

The increase in cardiac troponins has been shown to be associated with both a short- and long-term increase in mortality and rehospitalization rates [14-16]. In a recent post-hoc analysis from ADHERE, the increase of troponins ( $\mathrm{I}$ or $\mathrm{T}$ ) was found to be associated to a in-hospital mortality rate of $8 \%$ as opposed to $2 \%$ in patients with negative troponins $(p<0.001)$ [14]. We have reported that patients exhibiting an increase in plasma troponin $\mathrm{T}$ in at least one of daily serial measurements during an acute HF hospitalization had a threefold increase in 6 month mortality as compared to patients with no measurable troponin levels (31\% vs. 9\%, respectively; $p<0.001$ ) [15]. Measurement of plasma troponins may be a useful prognostic index and a potential surrogate of the effects of medical therapy on prognosis in patients with acute HF [18].

These findings regarding myocyte necrosis may have important implications for the selection of therapies for AHF. The use of agents with hemodynamic effects (vasodilators and inotropes) may precipitate/exacerbate a condition of myocardial ischemia and necrosis. With the exception of nitrates, usually proven to be safe because of their selective coronary vasodilating properties, other vasodilators, such as nitroprusside, nesiritide, and ularitide, may cause excessive arterial hypotension (along with "coronary steal" in the case of nitroprusside) with consequent coronary hypoperfusion. Inotropic agents are likely to cause myocardial damage to an even greater extent by inducing a significant increase in myocardial oxygen consumption and subendocardial ischemia (Fig. 2) [19]. These detrimental effects provide, at least in part, an explanation for the increased mortality associated with the early administration of nitroprusside in acute HF secondary to a recent AMI [20], and with the use of inotropes in patients with acute $\mathrm{HF}$ of ischemic etiology [21]. Inotrope administration alone [22], or in combination with vasodilators [23], was shown to be independently associated with an increased mortality in both ADHERE and in the Evaluation Study of Congestive Heart Failure and Pulmonary Artery Catheterization Effectiveness (ESCAPE) study.

\section{Systolic blood pressure}

The majority of patients admitted for acute HF present with normal or normal-high values of systolic blood pressure (SBP). Among the patients enrolled in the large international acute HF registries, a SBP at admission $>140 \mathrm{~mm} \mathrm{Hg}$ was observed in $45-50 \%$, a SBP of 120 to $140 \mathrm{~mm} \mathrm{Hg}$ in $40 \%$ and only $3-8 \%$ of the patients showed SBP $<90 \mathrm{~mm}$ $\mathrm{Hg}[2,3,5]$.

Elevated SBP during acute HF episodes may have at least two different pathophysiologic implications: 1) it may be a precipitating factor of $\mathrm{HF}$ through excessive vasoconstriction and increased afterload; or 2) it may be a consequence of neurohormonal activation and cardiac stimulation due to acute HF itself. The former is the case of an acute HF with a mainly vascular, rather than cardiac, pathogenesis, and elevated SBP becomes the principal target for therapy. This form is more common in women and the elderly, as well as in patients with preserved left ventricular ejection fraction [24-27]. It will be considered in greater detail in the next section.

Systolic blood pressure is a critical metric for targeting therapy in patients with acute HF. Patients with high SBP are sensitive to vasodilator therapy and usually do not need high diuretic doses as their main mechanism of dyspnea is fluid redistribution to the lungs rather than fluid accumulation [7-9,26-29]. Conversely, vasodilators and/or other agents with concomitant vasodilator activity should be used with extreme caution, if not at all, in patients with normal to low $\mathrm{SBP}$ on admission. In these patients the drop in SBP may cause a decline in blood flow to the myocardium or the kidney to critical levels with secondary organ damage and poor prognosis [7,28]. Excessive vasodilation with nesiritide or with levosimendan has been associated with untoward effects on renal function [30] and prognosis [31,32]. In recent phase II trials, the administration of new vasodilators such as relaxin has been attended by favourable effects on prognosis in patients with acute $\mathrm{HF}$ and $\mathrm{SBP}>125 \mathrm{~mm} \mathrm{Hg}$ using restrictive stopping rules of treatment when excessive SBP drops occurred [33].

\section{Fluid overload: accumulation versus redistribution}

The vast majority of patients with acute HF present with dyspnea and evidence of pulmonary and/or systemic congestion [34]. A progressive gain in body weight [35] and increase in ventricular filling pressures [36,37] may begin several days to weeks preceding the admission for HF. Zile et al. have recently assessed changes in estimated pulmonary artery diastolic pressure (ePAD) in patients who underwent implantation of a continuous intracardiac pressure monitoring device. An increase in ePAD was associated with episodes of acute decompensated HF both in patients with low LV ejection fraction (increase from $21 \pm 9$ to $24 \pm 8 \mathrm{~mm} \mathrm{Hg} ; p<0.05$ ) and in those with normal LV ejection fraction (increase from $17 \pm 7$ to $22 \pm 7 \mathrm{~mm} \mathrm{Hg} ; p<0.05$ ). No changes occurred in the patients who remained clinically stable.

Thus, increases in pulmonary pressure and pulmonary congestion are the main mechanism causing dyspnea and, ultimately, the hospitalization of patients with HF. These changes may, or may not, occur as a consequence of sodium and water retention and total body fluid overload. In fact, there are cases in which acute HF may occur 
Table 2

Comparison between two different clinical and pathophysiological profiles of acute

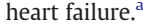

\begin{tabular}{|c|c|c|}
\hline & Vascular (peripheral) & Cardiac (central) \\
\hline Main mechanism of onset & $\uparrow$ afterload & $\begin{array}{l}\downarrow \text { contractility renal } \\
\text { hypoperfusion }\end{array}$ \\
\hline LVEF & Normal & Low \\
\hline Main cause of symptoms & $\begin{array}{l}\text { Fluid redistribution to } \\
\text { the lungs }\end{array}$ & Fluid accumulation \\
\hline $\begin{array}{l}\text { Gain in body } \\
\text { weight }\end{array}$ & No & Yes \\
\hline Onset & Rapid (hours) & Gradual (days) \\
\hline Main symptom & Dyspnea & Fatigue \\
\hline Main sign(s) & $\begin{array}{l}\text { Pulmonary congestion } \\
\text { (rales, oedema) }\end{array}$ & $\begin{array}{l}\text { Peripheral edema, } \\
\text { jugular venous stasis, } \\
\text { hepatomegaly }\end{array}$ \\
\hline Systolic BP & Normal or high & Normal or low \\
\hline LV filling pressure & High & $\begin{array}{l}\text { May be reduced by } \\
\text { low CO }\end{array}$ \\
\hline Cardiac output & Normal or high & Low \\
\hline \multicolumn{3}{|l|}{ Mortality ${ }^{\mathrm{b}}$} \\
\hline In-hospital & Low $(<5 \%)$ & High $(\geq 5 \%)$ \\
\hline 3-months & Relatively low (5-7\%) & High $(10-15 \%)$ \\
\hline $\begin{array}{l}\text { 3-months } \\
\text { re-hospitalizations }\end{array}$ & High $(30 \%)$ & High $(30 \%)$ \\
\hline
\end{tabular}

a Both may coexist in any patient though with a different magnitude in each individual

b Reported survival estimates are to be considered as non-absolute being the mortality also affected by other factors such as, for instance, mean length of hospital stay. BP = blood pressure; $\mathrm{CO}=$ cardiac output; and LVEF = left ventricular ejection fraction.

without salt and water retention and weight gain and the underlying mechanism is rather a redistribution of fluids to the lungs with pulmonary, but not systemic, congestion [24-27].

Vasoconstriction, rather than fluid retention, may play a pivotal role in these vascular forms of acute HF. Venoconstriction causes an increase in venous return to the right heart which by interacting with poorly compliant ventricles leads to a rise in end-diastolic pressures of both ventricles. Arterial vasoconstriction increases the left ventricular afterload with a reduction of stroke volume and further increase in intraventricular pressures. Vasoconstriction, particularly in the presence of diastolic dysfunction may cause an increase in pulmonary capillary pressure, pulmonary congestion and oedema. All of the above mechanisms may take place even in the absence of volume retention through a redistribution of fluid from the peripheral to the pulmonary circulation. The mechanisms underlying excessive vasoconstriction are not fully elucidated, to date, but neurohormonal activation and inflammation may have a central role [38]. A comparison between these 2 different pathophysiological and clinical profiles of acute HF is proposed in Table 2 .

Table 3

Common comorbidities in patients with acute heart failure.

\begin{tabular}{l}
\hline Cardiac \\
Coronary artery disease \\
Acute coronary syndrome \\
Chronic ischemic cardiac disease \\
Hypertension \\
Arrhythmias (atrial fibrillation, etc.) \\
Valvular disease (mitral regurgitation, etc.) \\
Non-cardiac \\
Chronic kidney disease \\
Chronic obstructive pulmonary disease \\
Diabetes mellitus \\
Anemia \\
Cachexia \\
Cerebrovascular disease \\
Depression \\
Dementia/cognitive dysfunction \\
$\ldots$
\end{tabular}

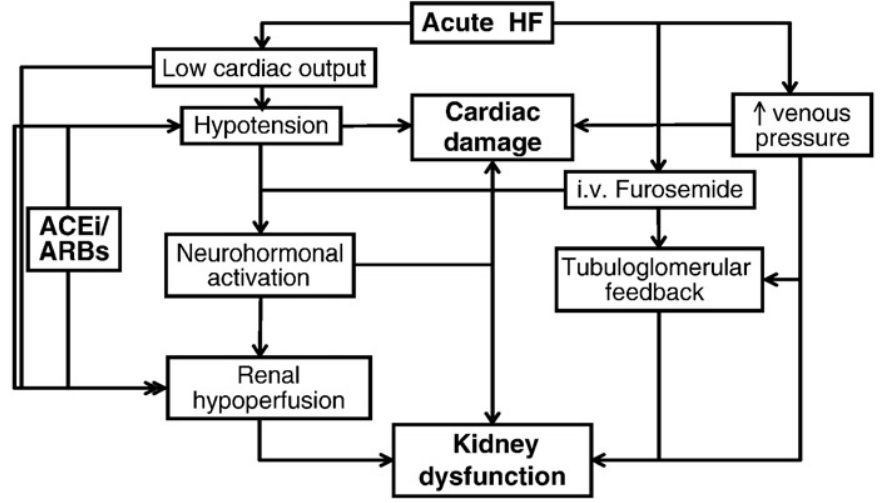

Fig. 3. Relations between heart failure and kidney dysfunction.

\section{Cardiac and non-cardiac comorbidities}

The prevalence of comorbidities is high in patients with acute HF and the most common ones are summarized in Table 3. Cardiac and non-cardiac conditions may be concomitant to or act as precipitating factors/triggers of acute HF and significantly affect its clinical manifestations and prognosis. Ischemic heart disease, arrhythmias, and valvular heart disease were frequent in patients from the EHFS II and represented each the precipitating factor of nearly one third of the total cases of acute HF [4].

As for non-cardiac comorbidities, chronic kidney disease has been reported to be present in $30-35 \%$, chronic obstructive pulmonary disease in $10-30 \%$, diabetes mellitus in $35-40 \%$, and anemia in $15-20 \%$ of the patients with acute HF. Amongst different comorbidities, renal dysfunction seems to be the one more likely to play a major role in the pathogenesis and prognosis of the patients with acute HF. A mild to moderate impairment of renal dysfunction is present in the majority of patients with acute HF. Kidney function is highly dependent on the patient's hemodynamics as demonstrated by studies showing the tight relation between renal function and both cardiac output and venous pressure (Fig. 3). The important role of renal venous pressure, in addition to cardiac output, as a major determinant of renal function has been recently shown [39-41]. Neurohormonal activation and concomitant therapy (namely, diuretics) may also play a major role in the development of kidney dysfunction in the patients with acute HF.

Multiple studies have shown that renal dysfunction is one of the most important determinants of prognosis, both in-hospital and postdischarge, in the patients hospitalized for acute HF [3,4,10,42]. Worsening renal function during hospitalization for acute HF is another determinant of a poor prognosis. Some degree of worsening renal function occurs, depending on the specific definition applied, in approximately $30 \%$ of the patients with acute HF and is associated with longer hospital stay, increased in-hospital mortality, and increased post-discharge mortality and re-hospitalizations $[43,44]$. We recently reported that an increase of $>25 \%$ and $>0.3 \mathrm{mg} / \mathrm{dL}$ from admission of serum creatinine levels is an independent predictor of post-discharge mortality in patients with acute HF (RR at multi-variable analysis, 1.47; $95 \% \mathrm{Cl}, 1.13-1.81 ; p=0.024)$. Administration of high doses of furosemide was among the main determinants of worsening renal function, although it is impossible to determine from observational data whether this is simply a marker of greater disease severity [45].

Renal dysfunction may contribute to the poor prognosis of the patients with acute HF through multiple mechanisms. These include increased neurohormonal activation and inflammation, intolerance to renin-angiotensin-aldosterone antagonists, increased fluid and sodium retention and resistance to loop diuretics [46]. Similar as with renal dysfunction, all of the comorbidities listed in Table 3 have been reported to be associated, generally in an independent fashion, with a worse prognosis in patients with acute HF and have been included in multi- 
variable models of risk prediction $[47,48]$. However, only intervention studies with drugs selectively targeting these comorbidities will be powered to definitely demonstrate whether such conditions directly contribute to the progression of HF or are just epiphenomena of a more severe disease state.

\section{Conclusions}

Patients with acute HF are a heterogeneous population with respect to both clinical profiles at presentation and pathophysiological mechanisms. Specific pathophysiologic substrates act as precipitating or concomitant factors in acute HF and significantly affect prognosis and represent targets for treatment. Treatment tailored to individual clinical presentations and pathophysiologic mechanisms will be more likely to improve prognosis of the patients with acute HF.

\section{Acknowledgement}

The authors of this manuscript have certified that they comply with the Principles of Ethical Publishing in the International Journal of Cardiology [49].

\section{References}

[1] Gheorghiade M, Zannad F, Sopko G, et al. Acute heart failure syndromes: current state and frame work for future research. Circulation 2005;112:3958-68.

[2] Adams Jr KF, Fonarow GC, Emerman CL, et al. Characteristics and outcomes of patients hospitalized for heart failure in the United States: rationale, design, and preliminary observations from the first 100,000 cases in the Acute Decompensated Heart Failure National Registry (ADHERE). Am Heart J 2005;149:209-16.

[3] Tavazzi L, Maggioni AP, Lucci D, et al. Nationwide survey on acute heart failure in cardiology ward services in Italy. Eur Heart J 2006;27:1207-15.

[4] Nieminen MS, Brutsaert D, Dickstein K, et al. EuroHeart Failure Survey II (EHFS II): a survey on hospitalized acute heart failure patients: description of population. Eur Heart J 2006;27:2725-36.

[5] Gheorghiade M, Abraham WT, Albert NM, et al. Systolic blood pressure at admission, clinical characteristics, and outcomes in patients hospitalized with acute heart failure. JAMA 2006;296:2217-26.

[6] Zannad F, Mebazaa A, Juillière Y, et al. Clinical profile, contemporary management and one-year mortality in patients with severe acute heart failure syndromes: the EFICA study. Eur J Heart Fail 2006;8:697-705.

[7] Gheorghiade M, Pang PS. Acute heart failure syndromes. J Am Coll Cardiol 2009;53:557-73.

[8] Dickstein K, Cohen-Solal A, Filippatos G, et al. ESC Guidelines for the diagnosis and treatment of acute and chronic heart failure 2008: the Task Force for the Diagnosis and Treatment of Acute and Chronic Heart Failure 2008 of the European Society of Cardiology. Developed in collaboration with the Heart Failure Association of the ESC (HFA) and endorsed by the European Society of Intensive Care Medicine (ESICM). Eur J Heart Fail 2008;10:933-89.

[9] Nieminen MS, Böhm M, Cowie MR, et al. Executive summary of the guidelines on the diagnosis and treatment of acute heart failure: the Task Force on Acute Heart Failure of the European Society of Cardiology. Eur Heart J 2005;26:384-416.

[10] Fonarow GC, Adams Jr KF, Abraham WT, et al. Risk stratification for in-hospital mortality in acutely decompensated heart failure: classification and regression tree analysis. JAMA 2005;293:572-80.

[11] Felker GM, Shaw LK, O'Connor CM. A standardized definition of ischemic cardiomyopathy for use in clinical research. J Am Coll Cardiol 2002;39:210-8.

[12] Reynolds HR, Hochman JS. Cardiogenic shock: current concepts and improving outcomes. Circulation 2008;117:686-97.

[13] Gurbel PA, Gattis WA, Fuzaylov SF, et al. Evaluation of platelets in heart failure: is platelet activity related to etiology, functional class, or clinical outcomes? Am Heart J 2002;143:1068-75.

[14] Peacock IV WF, De Marco T, Fonarow GC, et al. Cardiac troponin and outcome in acute heart failure. N Engl J Med 2008;358:2117-26.

[15] Metra M, Nodari S, Parrinello G, et al. The role of plasma biomarkers in acute heart failure. Serial changes and independent prognostic value of NT-proBNP and cardiac troponin-T. Eur J Heart Fail 2007;9:776-86.

[16] Horwich TB, Patel J, MacLellan WR, Fonarow GC. Cardiac troponin I is associated with impaired hemodynamics, progressive left ventricular dysfunction, and increased mortality rates in advanced heart failure. Circulation 2003;108:833-8.

[17] Gheorghiade M, Gattis Stough W, Adams Jr KF, Jaffe AS, Hasselblad V, O'Connor CM. The Pilot Randomized Study of Nesiritide Versus Dobutamine in Heart Failure (PRESERVD-HF). Am J Cardiol 2005;96(6A):18G-25G.

[18] Braunwald E. Biomarkers in heart failure. N Engl J Med 2008;358:2148-59.

[19] Schulz R, Rose J, Martin C, Brodde OE, Heusch G. Development of short-term myocardial hibernation. Its limitation by the severity of ischemia and inotropic stimulation. Circulation 1993;88:684-95.
[20] Cohn JN, Franciosa JA, Francis GS, et al. Effect of short-term infusion of sodium nitroprusside on mortality rate in acute myocardial infarction complicated by left ventricular failure: results of a Veterans Administration cooperative study. N Engl J Med 1982;306:1129-35.

[21] Felker MG, et al, for the OPTIME-CHF Investigators. Heart failure etiology and response to milrinone in decompensated heart failure: results from the OPTIMECHF Study. J Am Coll Cardiol 2003;41:997-1003.

[22] Abraham WT, Adams KF, Fonarow GC, et al. In-hospital mortality in patients with acute decompensated heart failure requiring intravenous vasoactive medications: an analysis from the Acute Decompensated Heart Failure National Registry (ADHERE). J Am Coll Cardiol 2005;46:57-64.

[23] Elkayam U, Tasissa G, Binanay C, et al. Use and impact of inotropes and vasodilator therapy in hospitalized patients with severe heart failure. Am Heart J 2007;153: 98-104.

[24] Cotter G, Moshkovitz Y, Milovanov O, et al. Acute heart failure: a novel approach to its pathogenesis and treatment. Eur J Heart Fail 2002;4:227-34.

[25] Milo-Cotter O, Adams KF, O'Connor CM, et al. Acute heart failure associated with high admission blood pressure-a distinct vascular disorder? Eur J Heart Fail 2007;9:178-83.

[26] Metra M, Dei Cas L, Bristow MR. The pathophysiology of acute heart failure-it is a lot about fluid accumulation. Am Heart J 2008;155:1-5.

[27] Cotter G, Metra M, Milo-Cotter O, Dittrich HC, Gheorghiade M. Fluid overload in acute heart failure-re-distribution and other mechanisms beyond fluid accumulation. Eur J Heart Fail 2008;10:165-9.

[28] Metra M, Teerlink JR, Voors AA, et al. Vasodilators in the treatment of acute heart failure: what we know, what we don't. Heart Fail Rev 2009;14:299-307.

[29] Cotter G, Metzkor E, Kaluski E, et al. Randomised trial of high-dose isosorbide dinitrate plus low-dose furosemide versus high-dose furosemide plus low-dose isosorbide dinitrate in severe pulmonary oedema. Lancet 1998;351:389-93.

[30] Sackner-Bernstein JD, Skopicki HA, Aaronson KD. Risk of worsening renal function with nesiritide in patients with acutely decompensated heart failure. Circulation 2005;111:1487-91

[31] Sackner-Bernstein JD, Kowalski M, Fox M, Aaronson K. Short-term risk of death after treatment with nesiritide for decompensated heart failure: a pooled analysis of randomized controlled trials. JAMA 2005;293:1900-5.

[32] Mebazaa A, Nieminen MS, Packer M. Levosimendan vs dobutamine for patients with acute decompensated heart failure: the SURVIVE randomized trial. JAMA 2007;297:1883-91.

[33] Teerlink JR, Metra M, Felker GM, et al. Relaxin for the treatment of patients with acute heart failure (Pre-RELAX-AHF): a multicentre, randomised, placebo-controlled, parallel-group, dose-finding phase IIb study. Lancet 2009;373:1429-39.

[34] Pang PS, Cleland JG, Teerlink JR, et al. A proposal to standardize dyspnoea measurement in clinical trials of acute heart failure syndromes: the need for a uniform approach. Eur Heart J 2008;29:816-24.

[35] Chaudhry SI, Wang Y, Concato J, Gill TM, Krumholz HM. Patterns of weight change preceding hospitalization for heart failure. Circulation 2007;116:1549-54.

[36] Adamson PB, Magalski A, Braunschweigh F, et al. Ongoing right ventricular hemodynamics in heart failure: clinical value of measurements derived from an implantable monitoring system. J Am Coll Cardiol 2003;41:565-71.

[37] Zile MR, Bennett TD, St John Sutton M. Transition from chronic compensated to acute decompensated heart failure: pathophysiological insights obtained from continuous monitoring of intracardiac pressures. Circulation 2008;118:1433-41.

[38] Colombo PC, Onat D, Sabbah HN. Acute heart failure as "acute endothelitis"interaction of fluid overload and endothelial dysfunction. Eur J Heart Fail 2008;10 (2):170-5.

[39] Mullens W, Abrahams Z, Francis GS, et al. Importance of venous congestion for worsening of renal function in advanced decompensated heart failure. J Am Coll Cardiol 2009;53:589-96.

[40] Damman K, Navis G, Smilde TD, et al. Decreased cardiac output, venous congestion and the association with renal impairment in patients with cardiac dysfunction. Eur J Heart Fail 2007;9:872-8.

[41] Damman K, van Deursen VM, Navis G, Voors AA, van Veldhuisen DJ, Hillege HL. Increased central venous pressure is associated with impaired renal function and mortality in a broad spectrum of patients with cardiovascular disease. J Am Coll Cardiol 2009;53:582-8.

[42] Nohria A, Hasselblad V, Stebbins A, et al. Cardiorenal interactions: insights from the ESCAPE trial. J Am Coll Cardiol 2008;51:1268-74.

[43] Damman K, Navis G, Voors AA, et al. Worsening renal function and prognosis in heart failure: systematic review and meta-analysis. J Card Fail 2007;13:599-608.

[44] Metra M, Nodari S, Parrinello G, et al. Worsening renal function in patients hospitalized for acute heart failure: clinical implications and prognostic significance. Eur J Heart Fail 2008;10:188-95.

[45] Felker GM, O'Connor CM, Braunwald E, for the Heart Failure Clinical Research Network Investigators. Loop diuretics in acute decompensated heart failure: necessary? Evil? A necessary evil? Circ Heart Fail 2009;2:56-62.

[46] Shlipak MG, Massie BM. The clinical challenge of cardiorenal syndrome. Circulation 2004;110:1514-7.

[47] Lee DS, Austin PC, Rouleau JL, Liu PP, Naimark D, Tu JV. Predicting mortality among patients hospitalized for heart failure: derivation and validation of a clinical model. JAMA 2003;290:2581-7.

[48] Senni M, Santilli G, Parrella P, et al. A novel prognostic index to determine the impact of cardiac conditions and co-morbidities on one-year outcome in patients with heart failure. Am J Cardiol 2006;98:1076-82.

[49] Coats AJ. Ethical authorship and publishing. Int J Cardiol 2009;131:149-50. 